\title{
An Introduction of Droplet Impact Dynamics to Engineering Students
}

\author{
Sara Moghtadernejad ${ }^{1, * \mathbb{C}}$, Christian Lee ${ }^{1}$ and Mehdi Jadidi ${ }^{2}$ \\ 1 Department of Chemical Engineering, California State University, Long Beach, CA 90840, USA; \\ Christian.Lee01@student.csulb.edu \\ 2 Department of Mechanical and Industrial Engineering, Concordia University, Montreal, QC H3G 1M8, \\ Canada; m_jadi@encs.concordia.ca \\ * Correspondence: sara.moghtadernejad@csulb.edu
}

Received: 1 June 2020; Accepted: 1 July 2020; Published: 2 July 2020

\begin{abstract}
An intensive training course has been developed and implemented at the California State University Long Beach based on 8 years of experience in the multiphase flow area with the specific focus on droplet-solid interactions. Due to the rapid development of droplet-based equipment and industrial techniques, numerous industries are concerned with understanding the behavior of droplet dynamics and the characteristics that govern them. The presence and ensuing characteristics of the droplet regimes (spreading, receding, rebounding, and splashing) are heavily dependent on droplet and surface conditions. The effect of surface temperature, surface wettability, impact velocity, droplet shape and volume on droplet impact dynamics, and heat transfer are discussed in this training paper. Droplet impacts on moving solid surfaces and the effects of normal and tangential velocities on droplet dynamics are other topics that are discussed here. Despite the vast amount of studies into the dynamics of droplet impact, there is still much more to be investigated as research has expanded into a myriad of different conditions. However, the current paper is intended as a practical training document and a source of basic information, therefore, the scope is kept sufficiently broad to be of interest to readers from different engineering disciplines.
\end{abstract}

Keywords: droplet impact; undergraduate education; applications of fluids

\section{Introduction}

This paper summarizes an intensive course on the subject of multiphase flow with the focus on both the theoretical and practical knowledge on droplet-solid interactions. More specifically, the goal of this training manuscript is to provide students with in-depth practical knowledge of droplet dynamics due to its numerous industrial and scientific applications. The dynamics of droplet impacts on solid surfaces has been studied for years starting with the work of Worthington [1,2]. To this day, droplet impact dynamics are widely studied as further improvements in understanding of droplet behavior due to the variety of their industrial applications. In particular, droplet impacts are imperative to industrial processes employing spray coating and painting, spray cooling, inkjet printing, combustion engines, and anti-icing characteristics of critical industrial components such as aircraft surface, powder lines, and wind turbines [3-7]. A brief discussion for some of these usages is presented below.

One of the prominent applications of droplet studies is aircraft icing, which refers to creation of ice on the surface of flying objects. This usually happens at the presence of super-cooled water droplets and below icing temperature. Those droplets are formed as droplets with various size merge in clouds, or when the falling snow melts as it passes through a warmer layer (weather inversion). In either case, they are very unstable, and any disturbance will cause ice formation. During a flight, a fraction of super-cooled droplets tracks through the airflow and impact the aircraft surface. In most cases, the low 
energy droplets freeze upon impact, whereas the ones with higher energy flow along the surface until their energy is depleted and then freeze. Consequently, the resulting ice changes the surface structure of the aircraft and this reduction in the aerodynamic of the wing increases the fuel consumption [8-13]. As such, a detailed understanding of this process is much needed to engineer more efficient wings.

Other application of droplets is in direct injection combustion engines, where the behavior of fuel droplet impingement on the piston and surrounding cylinder walls is heavily studied [14-18]. The formation of the wall-fuel film and the improvement in the efficacy of combustion engine promote a wide variety of research into droplet dynamics [14-18]. The properties of superhydrophobic surfaces are of major interest in aerospace and power industries for their anti-icing characteristics, to prevent ice formation on wind turbine blades, power-lines, or aircraft wings [11,19-21]. Methods improving the repulsion of water droplets off surfaces have been heavily studied. Such methods involve variable surface inclination and application of superhydrophobic coatings [4,22-26].

Another interesting application of droplet dynamics is in the thermal spray process, where molten or semi-molten metal and ceramic particles are deposited on a substrate to generate various types of coatings such as thermal barrier, wear resistance, and corrosion resistance ones [27-32]. During the thermal spray process first, a heated gas is created via chemical combustion or electrical energy in a torch. Then the gas is used to melt the coating powder or wire into droplets and accelerate them toward a substrate, where the particles generate a splat. Finally, a coating is formed via multiple layers of splats. In that regards, most research studies the effect of droplet's inflight behaviors such as velocity, temperature, and trajectory, and their interaction with the substrate's temperature and roughness on the process of droplet solidification and coating structure [27-31,33-38].

Yet another importance of fundamental study in the droplet impact field is its application in spray cooling, where an array of small droplets is applied to a heated surface as a cooling mechanism to enhance its heat transfer [39-44]. In this operation, the cooling effectiveness is strongly influenced by fluid properties and droplet's size and velocity. Amongst the numerous usages here are dermatological operation, fire protection, and cooling of hot surfaces like hot strip mill and high-performance electronic devices. For example, cryogenic spray cooling is selectively directed to pre-cool human skin in laser treatments and hair removal procedures. Similarly, in steel strip casting, a jet gas with water droplets is guided to cool a high temperature (up to $1800 \mathrm{~K}$ ) steel surface that shapes the final microstructure optimization. All in all, new developments in spray cooling technology demand improving the heat transfer rate, while maintaining uniform heat removal, and preventing temperature overshoot. They also require uniform operating temperatures maintenance, the removal of high heat flux, or the adaptability to changes in heat flux $[39,42,45]$.

Furthermore, droplet dynamics are widely used in ink-jet printing as it involves the generation and deposition of small droplets, usually containing colorants, onto a substrate in certain patterns. Main challenges in the process are when droplets bounce back or spread unevenly on the paper. The development in understanding droplet dynamics is thus motivated by the vast applications of ink-jet printing, where improvements in droplet positioning, volume, and directionality are the main concerns [46-48]. Note that, the input substance (ink) can be a tiny liquid of "smart" material. As such today's applications of ink-jet technologies include printing solar cells, medical sensors, and electronic circuits. Particularly, ink-jet printing techniques have rapid developments in medical industry, where the manipulation of small amounts of liquid is essential in cell culture growth and pharmaceutical drug production [49-51].

Lastly, there has been rapid developments in microfluidic technologies, where liquid drops are handled on nano or micro scales. Microfluidic technologies have heavily impacted the biomedical, environmental, food, and chemical industries [52-54]. Other notable industrial applications of droplet impacts include quenching of aluminum alloys and steel, fire suppression, incinerators, soil erosion, and crop spraying [3,55-58]. 


\section{Key Dimensionless Numbers in Droplet Impact Dynamics}

To facilitate the characterization of droplet dynamics several dimensionless numbers have been introduced in the literature. The main dimensionless numbers are given in Table $1[3,59,60]$, where $\rho_{l}$ denotes the liquid density, $d_{0}$ is the droplet diameter, $u_{0}$ is the droplet impact velocity, $\sigma$ is the surface tension, $\mu_{l}$ is the liquid viscosity, $g$ is the gravity, and $t$ is time. Furthermore, in this table, $d_{c l}, c_{l}, k_{l}$, $T_{0}, h_{l v}, Q$, and $M_{\text {evap }}$ denote the diameter of the wetted region, liquid specific heat, liquid thermal conductivity, initial temperature, enthalpy of vaporization, total heat that is transferred to the droplet, and the evaporated mass at a given time, respectively. Subscripts $l$ and $s$ also stand for liquid and solid, respectively. It is worth mentioning that Table 1 only covers the main dimensionless numbers, while additional dimensionless numbers can be defined for the contact angle of the droplet on the surface, the boundary layer thickness, vapor properties, etc.

Table 1. Key dimensionless numbers to study droplet impact dynamics.

\begin{tabular}{cc}
\hline Dimensionless Number & Formulation \\
\hline Weber number (ratio of inertial to surface tension forces) & We $=\frac{\rho_{l} d_{0} u_{0}^{2}}{\sigma}$ \\
\hline Reynolds number (ratio of inertial to viscous forces) & $R e=\frac{\rho_{l} d_{0} u_{0}}{\mu_{l}}$ \\
\hline Ohnesorge number & $O h=W e^{0.5} R e^{-1}$ \\
\hline Bond number (ratio of gravitational to surface tension forces) & $B o=\frac{\rho_{l} g d_{0}^{2}}{4 \sigma}$ \\
\hline Dimensionless time & $\tau=\frac{u_{0} t}{d_{0}}$ \\
\hline Spreading ratio & $S=\frac{d_{c l}}{d_{0}}$ \\
\hline Prandtl number & $P r=\frac{\mu_{l} \mathcal{C}_{l}}{k_{l}}$ \\
\hline Stefan number & $S t=\frac{c_{l} \Delta T_{0}}{h_{l v}}$ \\
\hline Ratio of the thermal effusivity of the liquid and the solid & $R_{e f f}=\frac{\sqrt{(\rho c k)_{l}}}{\sqrt{(\rho c k)_{s}}}$ \\
\hline Ratio of the total heat $Q$ transferred to the droplet to the maximal \\
possible heat transfer
\end{tabular}

\section{Droplet Impact on Static Solid Surfaces}

Experimental investigations suggest the presence of six possible regimes for droplet impact on dry surfaces, including deposition, receding breakup, rebound, and splashing (see Figure 1). The characteristics of these regimes after droplet impact has been deeply investigated [3,57,59,61-64]. The presence, or lack of each regime is dependent upon multiple conditions of the impacting droplet and characteristics of the surface. Such properties include impact velocity, droplet size, liquid surface tension and viscosity, surface temperature, wettability [3,4], etc. 


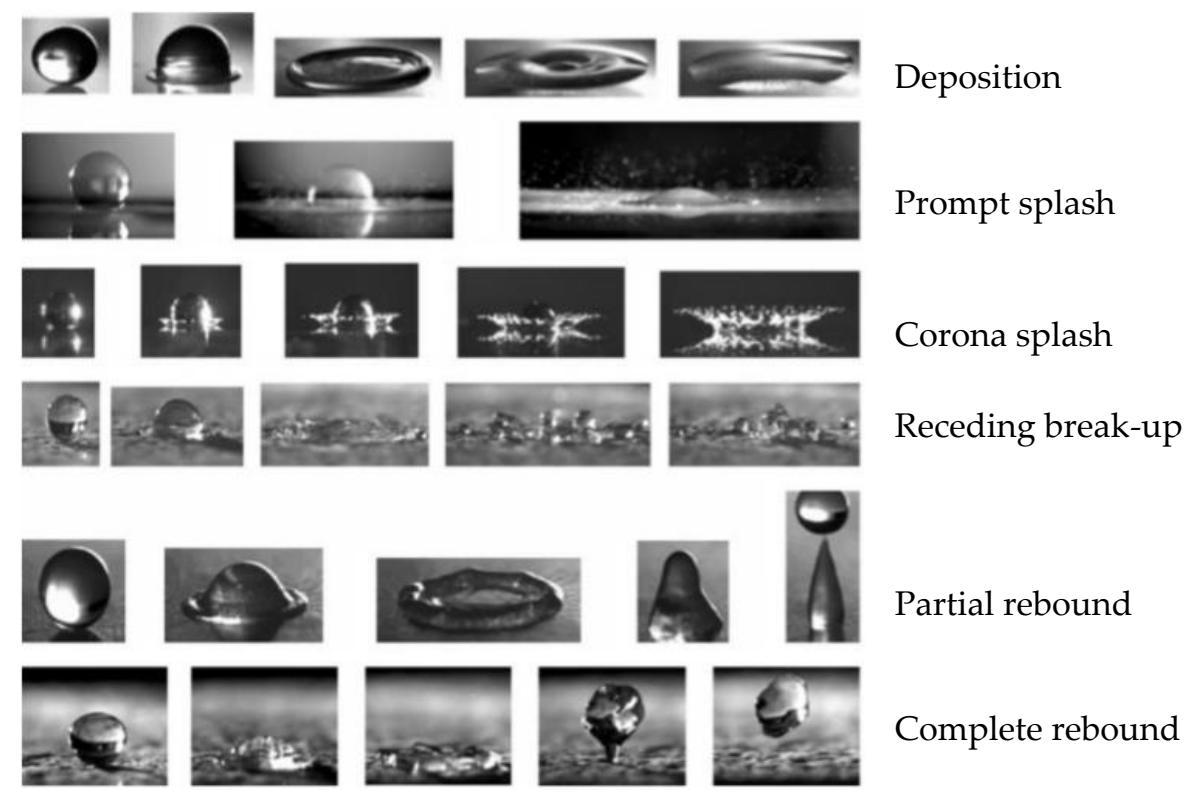

Figure 1. Droplet impact regimes on dry surfaces (reproduced with permission from [65]).

The expansion of the droplet after its impact on the surface is known as the spreading regime. This phenomenon is observed at relatively low Weber number values and low surface temperatures $[3,63,66]$. One of the most important parameters for characterizing the spreading regime during the droplet impact is the maximum spreading diameter of the droplet. The maximum spreading diameter of the droplet is imperative when heat transfer is a concern as the maximum spreading defines how much surface area is available for heat transfer [66]. Several characteristics of both the droplet and surface can affect the maximum spreading, such as droplet impact velocity and surface wettability [67-70]. Initial droplet velocity heavily impacts its spreading. As the droplet impacts on the surface, the kinetic energy in the vertical direction is transferred to the radial direction, promoting the spreading of the droplet. Lann et al. [69] described in their work that droplets spreading behavior is overseen by the conversion of kinetic energy into surface energy or dissipated heat. Different models have been developed to predict the maximum spreading ratio, $S_{\max }=d_{c l, \max } / d_{0}$, as a function of the impact parameters. Some of the most commonly used formulas in the literature are as follows:

Jones [71]

$$
S_{\max }=\sqrt{\frac{4}{3} R e^{1 / 4}}
$$

Chandra and Avedisian [72]

$$
\frac{3 W e}{2 R e} S_{\max }^{4}+(1-\cos \theta) S_{\text {max }}^{2}-\left(\frac{W e}{3}+4\right)=0
$$

Asai et al. [73]

$$
S_{\max }=1+0.48 W e^{0.5} \times \exp \left[-1.48 W e^{0.22} R e^{-0.21}\right]
$$

Pasandideh-Fard et al. [74]

$$
S_{\max }=\sqrt{\frac{W e+12}{3\left(1-\cos \theta_{A}\right)+4(W e / \sqrt{R e})}}
$$

Mao et al. [75]

$$
\left[\frac{1}{4}(1-\cos \theta)+0.2 \frac{W e^{0.83}}{R e^{0.33}}\right] S_{\max }^{3}-\left(\frac{W e}{12}+1\right) S_{\max }+\frac{2}{3}=0
$$


Ukiwe and Kwok [76]

$$
(W e+12) S_{\text {max }}=8+S_{\text {max }}^{3} \times\left[3\left(1-\cos \theta_{A}\right)+4 \frac{W e}{\sqrt{R e}}\right]
$$

where $\theta_{A}$ stands for the advancing contact angle.

The receding regime involves the contraction of the droplet once it has reached the maximum spreading. Droplet receding is due to the liquid surface tension, which pulls the droplet together $[3,66]$. The receding time depends on several factors including the surface shape and the liquid surface tension $[67,77]$. The suppression of this regime has also been observed under various conditions. For example during the impact of liquid fuels such as decane, ethanol, and tetradecane due to their low surface tension, the contraction phase is suppressed [77]. This regime has also been shown to be heavily affected by surface temperature. Receding can be hindered or even vanished by sufficiently low surface temperatures. For instance, during the water droplet impact on ice films, once the droplet reaches maximum spreading, the contact interface between the droplet and the ice film freezes, preventing the formation of a receding regime [78-82].

After receding, the droplet may show rebounding depending on various parameters such as surface wettability, temperature, and kinetic energy. In the rebound regime, if the droplet has a high contact angle and sufficient kinetic energy, it may bounce off the surface. The rebound regime has also been shown to be absent under various conditions. For instance, upon impact on a super-cooled superhydrophobic surface, water droplet freezes and adheres to the surface as it spreads, therefore, no rebounding occurs [83].

The appearance of the splashing regime is also dependent on various conditions of the droplet and surface. During impact with high enough energy, the droplet hits the surface and disintegrates into secondary droplets. Splashing can be induced by changing the orientation of the surface, such as having spherical or inclined surfaces, or impact on a moving liquid film [84-86]. There are several types of splash such as corona, prompt, and fingering within the splashing regime [77,87-89]. In corona splashes (see Figure 1) the outer rim of the lamella lifts off the surface forming a crown. From the crown, the lamella breaks apart forming secondary droplets. In prompt splashes, the droplet disintegrates, and secondary droplets form immediately after impact. Finally, in fingering splashes, protrusions extend from the droplet, eventually disintegrating and forming secondary droplets [77,87-89]. Various boiling regimes have also been experimentally studied at super-heated temperatures. This causes different splash phenomena, such as boiling-induced breakup or boiling-induced splashing, due to nucleate boiling in the contact interface [66].

As mentioned earlier in this manuscript, the regimes and phenomena observed during droplet impact significantly depend on a variety of droplet/surface conditions. Here we aim to describe the key conditions affecting the impact dynamics of droplet on solid substrates. As such the article is divided into two sections describing the droplet impacts on (1) stationary solid surfaces and (2) moving solid surfaces. Noting that due to the vast number of characteristics defining the behavior of droplets only the major ones will be discussed in this article; namely impact velocity, droplet shape and size, surface wettability, and temperature.

\subsection{Effect of Surface Temperature}

Surface temperature is an important characteristic affecting the dynamics of impacting droplets, particularly when heat transfer is a concern. In the case of a hot, dry solid surface, the droplet impact outcomes are classified into several regimes: evaporation, nucleate boiling, foaming, transitional boiling, and film boiling. In the nucleate boiling regime, which occurs at relatively high surface temperatures, the droplet is in direct contact with the surface and vapor bubbles are formed at various isolated nucleation sites. These bubbles rise and the droplet will eventually boil off (see Figure 2b) [67]. In the foaming regime, which is a subcategory of nucleate boiling, the entire drop starts to foam. The vapor bubbles grow much larger in this regime while no separation from the liquid-gas interface 
and no coalescence are detected. In the transition boiling, due to high wall temperature, the generation rate of the vapor bubble increases quickly. Owing to bubbles coalescence, a vapor layer is formed over some portions of the area between the drop and the surface, while the rest of the drop wets the surface. In this regime, liquid layers frequently collapse, therefore, this regime is very unstable and secondary droplets are also generated [90]. Further increasing the temperature changes the regime to film boiling. In this regime, a vapor layer forms preventing the complete contact between the liquid and the surface [67]. In the film boiling regime, the droplet levitates on a vapor layer, as shown in Figure 3. This phenomenon is heavily studied and called the Leidenfrost effect [91]. The Leidenfrost effect also promotes rebounding of the droplet without disintegration into secondary droplets.

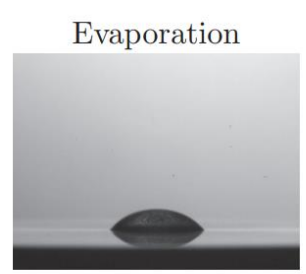

(a)

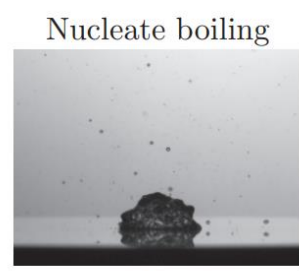

(b)

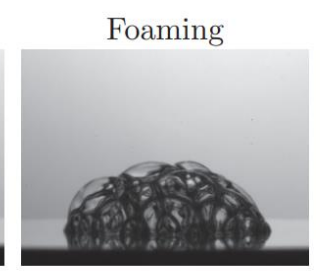

(c)

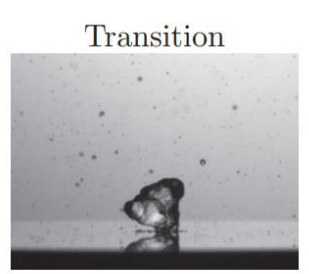

(d)
Film boiling

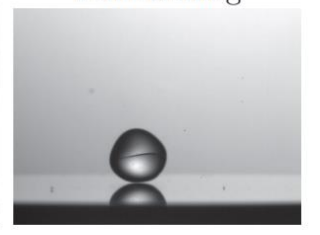

(e)

Figure 2. Outcomes of droplet collision with a hot, dry solid surface: (a) evaporation, nucleate (b) boiling, (c) foaming, (d) transition, and (e) film boiling (reproduced with permission from [90]).

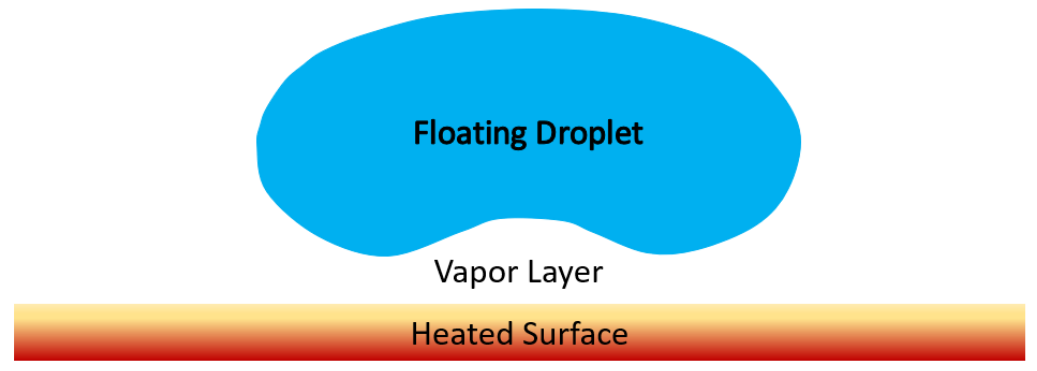

Figure 3. The Leidenfrost phenomenon forms vapor layer preventing droplet from contacting the surface.

One important characteristic of heat transfer in droplet dynamics is the evaporation time. When the surface temperature is within the nucleate boiling regime, it was observed that as surface temperature increases, the evaporation time decreases due to an increase heat transfer. During the transitional regime, the evaporation time is variable due to uneven contact between the liquid and surface. However, in the film boiling regime, the evaporation time sharply increases due to the Leidenfrost effect. When the droplet enters the film boiling regime, it is no longer in contact with the surface as the vapor layer separates the two. This vapor layer acts as an insulating layer, slowing down evaporation [67]. Further increasing the temperature past the Leidenfrost effect will decrease the evaporation time [92].

Liquid surface tension has significant influence on the dynamic Leidenfrost temperature. The dynamic Leidenfrost temperature is the minimum surface temperature at which the impacting droplet bounces without splashing, in other words the minimum temperature to induce the Leidenfrost effect [93]. Chen et al. [93] studied the effects of surfactants on the dynamic Leidenfrost temperature. In these sets of experiments alcohol surfactants, octanol and ethyl-hexanol, were added to water droplets causing a reduction in surface tension of the droplet. As a result, the maximum spreading diameter increased during the spreading regime. Additionally, it was observed that the time to reach maximum spreading was decreased. Chen et al. [93] found that by adding surfactants the dynamic Leidenfrost temperature increased. The addition of surfactants promotes splashing and prevents the formation of vapor layer. The reduced surface tension promotes a thinner lamella during spreading, this makes it easier for vapor bubbles to burst out from the boiling film and break the vapor layer, preventing the Leidenfrost state [93]. The reduced surface tension also makes it difficult for 
vapor bubbles to coalesce and form a vapor layer as a result of the lower bubble departure diameter. The dynamic Leidenfrost temperature can also be raised higher by increasing the concentration of surfactants in the droplet due to increased reduction in surface tension. Surface wettability is another parameter that affects the Leidenfrost point in a way that more hydrophilic surface leads to a higher Leidenfrost temperature $[67,90]$.

Cooled and super-cooled surface temperatures also have an intense effect on droplet dynamics. At sufficiently cool temperatures, droplets begin to nucleate and freeze. The sessile droplet undergoes a complex solidification process, typically split into five stages $[83,94,95]$, which is similar to the freezing of suspended water droplets. First, the droplet is cooled from its initial temperature to temperatures below the equilibrium freezing temperature during a cooling stage. Second, the droplet experiences a nucleation stage, where ice crystal nucleation occurs. Third, rapid crystal forms from the nucleation points driven by supercooling during the recalescence stage until it reaches the equilibrium temperature. Fourth, crystal growth is driven by heat transfer until the droplet is completely frozen during the freezing stage. Lastly, during the solid cooling stage, the temperature of the solidified droplet decreases due to the continuous cooling of the cold plate $[83,94,95]$. At this stage the ensuing droplet forms a peculiar shape with a pointed tip as shown in the last sequence of Figure 4.

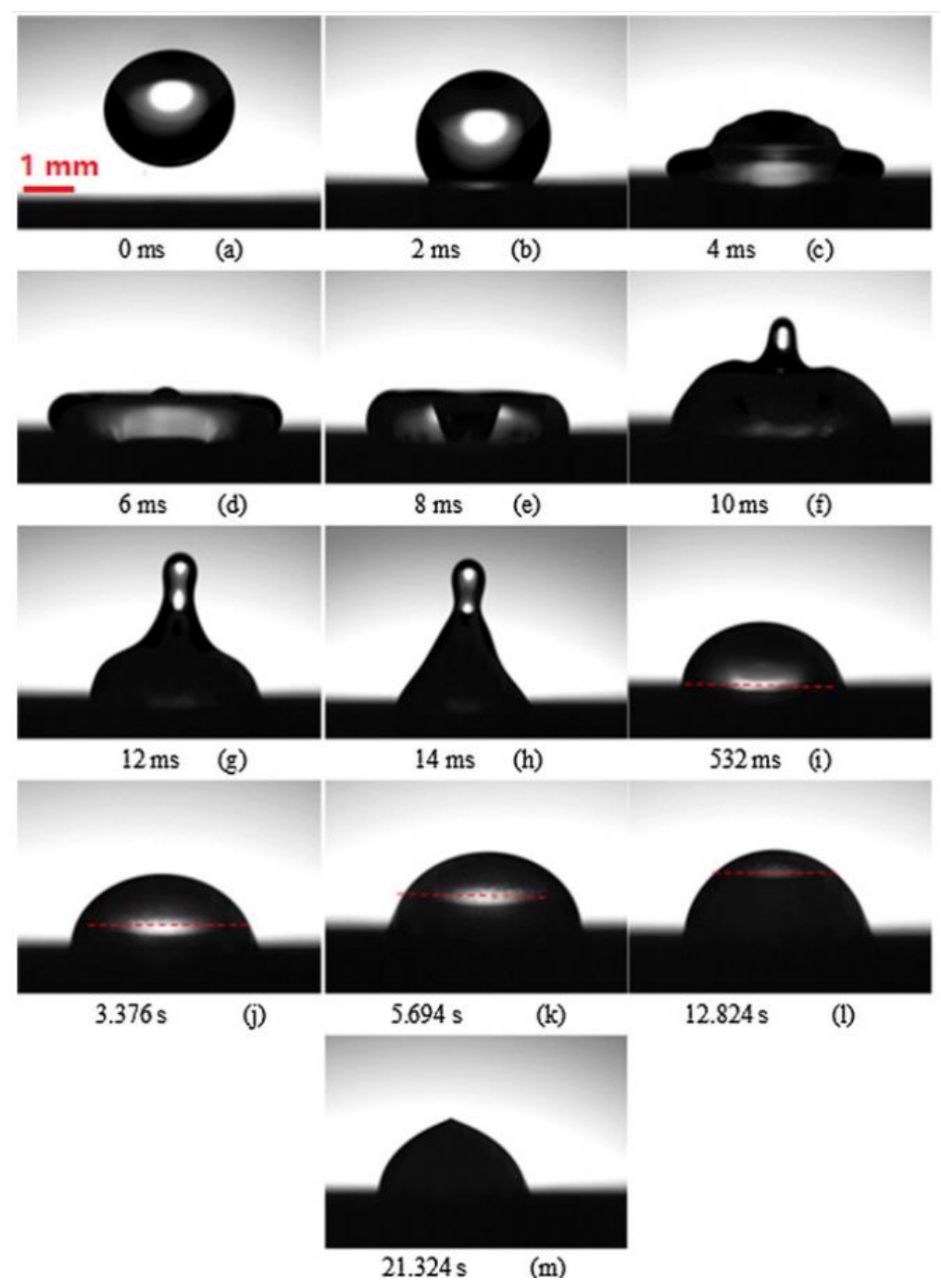

Figure 4. Sequences of water droplet impact on a cold hydrophobic surface, in a way (a-m): the starting point of the process to the end of the phenomenon. Droplet diameter $=2.82 \mathrm{~mm}$, impact velocity $=0.77 \mathrm{~m} / \mathrm{s}$, and surface temperature $=-10^{\circ} \mathrm{C}$ (reproduced with permission from [68]). 
The deformation of an impacting water droplet throughout the freezing process on a hydrophobic horizontal surface is shown in Figure 4. Experimental studies have shown that sub-cooled temperature has no significant effect on the spreading of the droplet after impact $[80,96]$. However, it shows significant suppression of the receding speed and height when the period of receding is sufficiently long $[96,97]$.

\subsection{Effect of Surface Wettability}

Surface wettability is the ability of surface to be wetted by a liquid and is mainly determined by surface roughness and chemistry. The Wenzel [98] and Cassie-Baxter [99] states describe the droplet wetting regime on the surface (see Figure 5). In the Wenzel state, water penetrates into the surface structures and conforms to the surface while in the Cassie-Baxter state, the water droplet remains above the surface structures, maintaining an almost spherical shape [4].
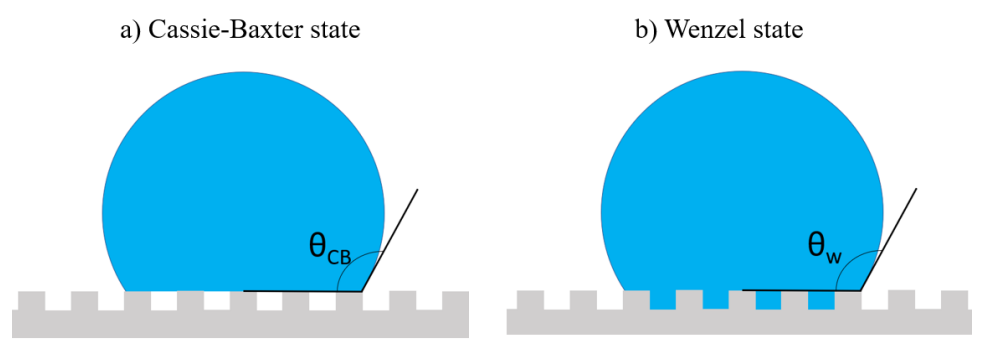

Figure 5. Wetting regimes of droplet on a solid surface: (a) Cassie-Baxter state and (b) Wenzel state (reproduced with permission from [4]).

Static contact angle, $\theta$, which is defined as the angle between the droplet and the surface at the contact line (see Figure 6) is a characteristic used to define the degree of surface wettability. The advancing contact angle, $\theta_{A}$, is the contact angle for a droplet with an advancing contact line (e.g., for a growing droplet), while the receding contact angle, $\theta_{R}$, is the contact angle for a receding contact line (e.g., a shrinking droplet). Contact angle hysteresis is defined as $\theta_{A}-\theta_{R}$ and is an indication of the droplet mobility on the surface, in a way that the lower is the hysteresis the easier the droplet moves on the surface (higher mobility). In general, in contact with water, a hydrophilic surface displays a contact angle of less than $90^{\circ}$, while a hydrophobic surface shows a contact angle of more than $90^{\circ}$. On a superhydrophobic surface, contact angle is more than $150^{\circ}$, and the contact angle hysteresis should be less than $10^{\circ}[4,68]$.

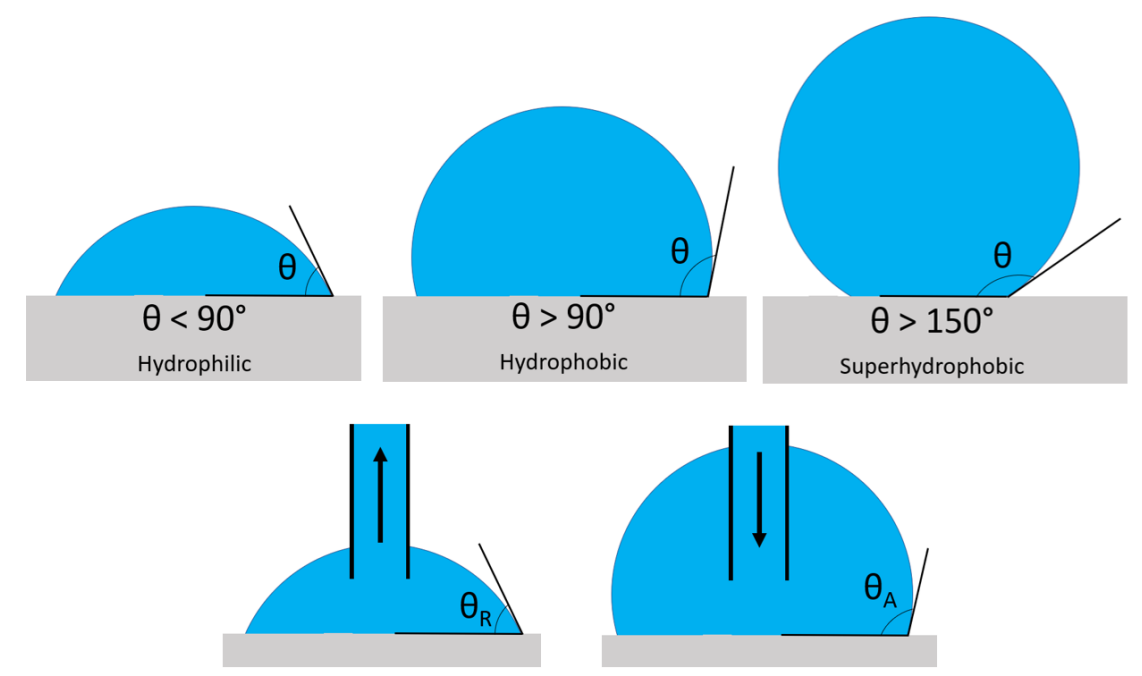

Figure 6. Schematic of static, $\theta$, receding, $\theta_{R}$, and advancing, $\theta_{A}$, contact angles [100]. 
The wettability of a surface considerably affects the droplet dynamics after impact. It is shown that the wetted area during the spreading regime decreases with lower surface wettability [68]. It is also found that as wettability decreased a longer time was required for a droplet to reach equilibrium. This is due to oscillations in the droplet as more kinetic energy remains after the spreading regime. As spreading is suppressed, less energy is dissipated [68]. Tang et al. [77] studied the droplet dynamics of various liquid on surfaces with variable roughness. It was shown that as surface roughness increases, the droplet has a slower spreading time and smaller maximum spreading diameter. It was also observed that increase of surface roughness, promotes droplet splashing. Moreover, it was demonstrated that surface roughness has a prominent impact on the promotion of splashing in liquids with a smaller Ohnesorge number.

Surface wettability has a significant impact on the heat transfer rate in droplet dynamics. Pan et al. [68] studied droplet impacts on cold surfaces and observed how wettability affects the freezing process. As surface wettability decreases the total icing time of the droplet increases. This is because of a lower heat transfer rate due to a smaller heat transfer area. The lower surface contact area is due to the high interfacial tension in low wettability surfaces, which prevents droplet spreading. As expected, on hydrophilic surfaces the total freezing time is shorter comparing to the hydrophobic surfaces. On hydrophilic surfaces spreading is promoted due to more heat transfer area. Overall, more contact surface area leads to a higher heat transfer rate and in turn a shorter freezing time [68].

Surface wettability also has an impact on the boiling process during droplet dynamics. In general, as wettability increases the rate of phase-change heat transfer enhances [92,101]. As surface becomes more hydrophilic, smaller and faster bubble growth occurs [102,103]. Kim et al. [92] studied the effects of surface wettability on droplet rebounding on hot surfaces above the Leidenfrost temperature. In their experiments four surfaces were prepared, a smooth hydrophilic, a smooth hydrophobic, a hydrophilic, and a hydrophobic surface both with nanoscale structures. For both smooth and nanoscale hydrophobic surfaces, rebounding of the droplet was achieved, but at varying surface temperatures. For both hydrophilic surfaces, it was found that a higher surface temperature was needed to induce rebounding as more energy was required to disperse the droplet from the surface. On hydrophilic surfaces, there is more contact area and more surface tension, thus more work is needed to break the droplet adherence to the surface. Finally, on the nanoscale hydrophilic surface, splashing was induced caused by the capillary effects and cavities of the surface [92].

\subsection{Effect of Impact Velocity}

One of the most important characteristics affecting the dynamics of droplet impact is the droplet impact velocity. Specifically, impact velocity has a profound effect on the droplet spreading regime. Clearly, when the impact velocity increases, more kinetic energy is given to the droplet. The momentum in the vertical direction is then transferred in the radial direction upon impact $[3,67,68]$. As higher impact velocities a higher degree of spreading is promoted, leading to more surface area for heat transfer $[62,66-68,93,104]$. Rajesh et al. [67] showed that on superheated concave and convex surfaces, an increase in impact velocity translated to an increase in both maximum droplet spreading and contact time. This increase in maximum spreading diameter is due to a rise in impact kinetic energy allowing the droplet to spread more. Similarly, the increase in maximum droplet spreading, due to higher impact velocity, affects the freezing time of the droplet on cold surfaces. With higher impact velocities, a trend of shorter icing time and faster freezing is observed (faster spreading and higher heat transfer dispersal occurs upon impact [68]). Furthermore, as mentioned above, if the droplet has enough energy, it rebounds after retraction. Increase of the impact velocity has shown to promote rebounding and further increase of the impact velocity can induce splashing [3,59]. Chen et al. [93] studied the effect of the initial droplet impact momentum on the Leidenfrost point and detected that at high impact velocity, a higher surface temperature is needed to induce the Leidenfrost effect. The increased droplet impact momentum leads to higher kinetic energy in the spreading droplet, this causes a thinner liquid disk, hence nucleate bubbles are easier to burst out from the disk, which breaks the Leidenfrost state [93]. 


\subsection{Effects of Droplet Shape and Volume}

The shape of the droplet can impact its dynamics and the heat transfer rate. By increasing the ellipticity and asymmetry of the droplet, the spreading and retraction regimes are significantly changed. Generally, asymmetrical droplets require a higher impact velocity for rebounding [105-108]. Yun [109] studied the effects of asymmetry and ellipticity on droplet dynamics, specifically on its rebound regime. Asymmetric droplets, in the shape of an egg, showed uneven spreading and retraction in both the $x$ and $y$ axis (see Figure 7). To investigate the effect of asymmetry and ellipticity on the rebound regime, the height of the droplet at the center of mass was measured. It was found that with increasing ellipticity the height of the droplet decreased [109]. Additionally, with decreasing asymmetry the droplet showed a reduced rebound height. This suggests that suppression of droplet rebound can be induced by variances in its ellipticity and asymmetry. In other words, the degree of droplet deposition can be promoted with variances in the droplet's shape. The suppression of droplet bouncing is due to a break in the horizontal momentum of the droplet at low asymmetry and high ellipticity [109].

(a)

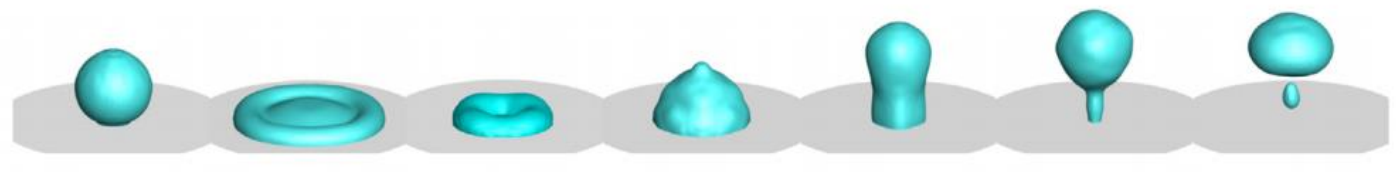

(BV)

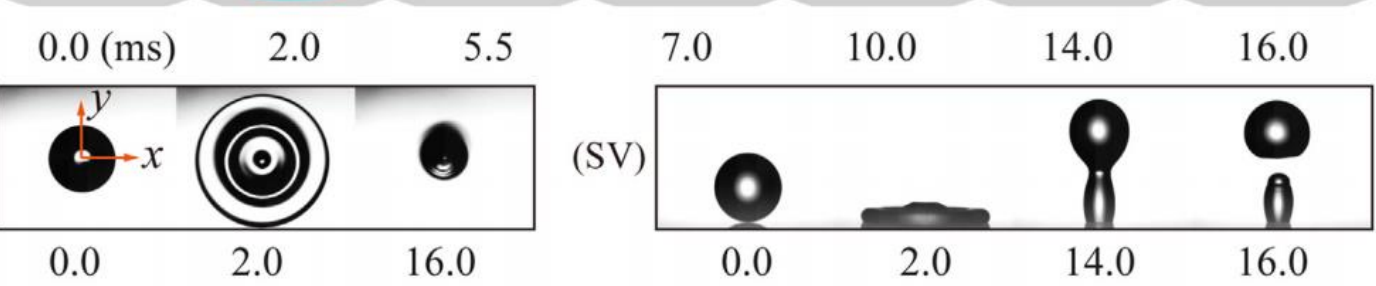

(b)
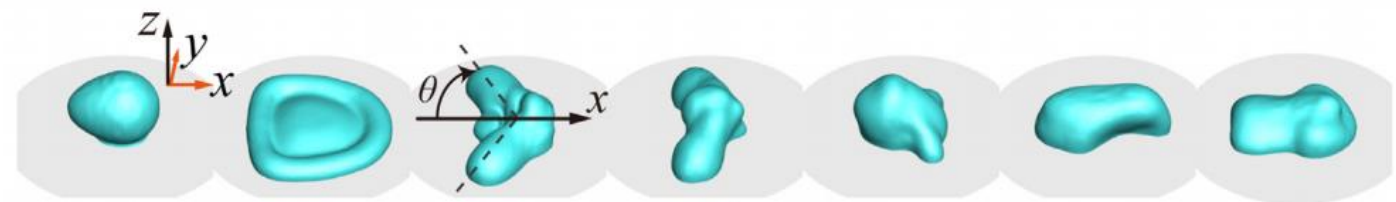

$0.0(\mathrm{~ms})$

2.0

5.5

7.0

10.0

12.0

14.0

(BV)

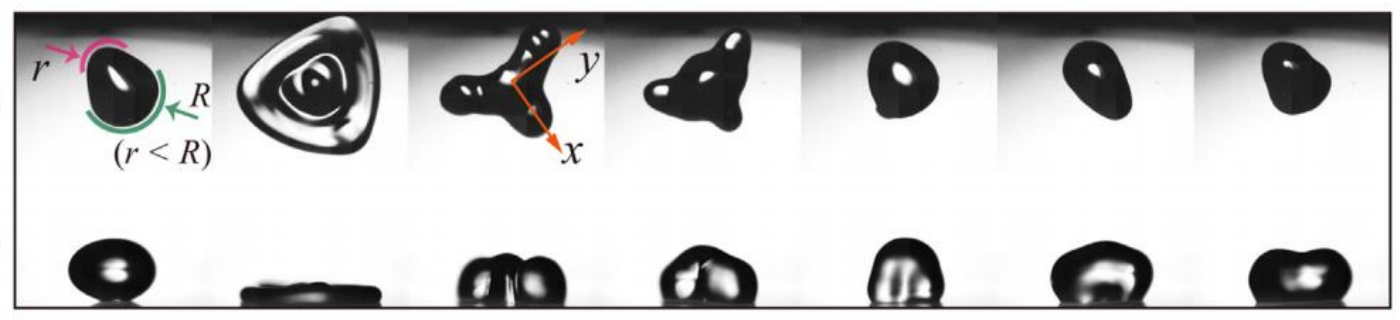

Figure 7. Simulation and experimental snapshots of the impact dynamics of (a) spherical and (b) asymmetric droplets on a hydrophobic surface (reproduced with permission from [109]); the equivalent droplet diameter is $2 \mathrm{~mm}$ and $W e=17$. SV and BV stand for the side and bottom-views in the experiment, respectively.

The size of the impacting droplet can also affect multiple characteristics of droplet dynamics. Pan et al. [68] studied how the initial droplet diameter affected its maximum spreading diameter and heat transfer rate. By increasing the initial droplet size, water droplet spreads more and showcases more oscillation during the spreading regime owing to an increase in initial kinetic energy. Additionally, upon impact on a cold surface, larger droplets showed increase in freezing time. Despite an increase in surface area during the spreading regime, larger droplets needed a longer time to freeze due to an increase in mass [68]. This experiment demonstrated the predominance of droplet volume over the effects of droplet dynamics on freezing time due to longer time spent during the heat transfer process 
compared to the droplet dynamic process. It is worth mentioning that an increase in droplet volume can induce splashing due to an increase in the Weber number.

\subsection{Effect of Relative Humidity}

Relative humidity has considerable influence on droplet dynamics. Bobinski et al. [110] qualitatively observed the effects of relative humidity and surface temperature on droplet impact in icing conditions. In their studies, relative humidity was kept constant and equal to $75 \%$, while the surface temperature was reduced to $-10{ }^{\circ} \mathrm{C}$. It was found that droplet freezing is triggered during the spreading phase and it freezes when the maximum spreading is reached, even on the superhydrophobic surface. By decreasing the relative humidity to $9 \%$, it was shown that the impact process on the superhydrophobic surface is similar to the case of room temperature tests and the droplet does not freeze. Experimental study was also performed by Jadidi et al. [111] to understand the effects of relative humidity, surface temperature, and wettability, and the frosting mechanism on water droplet impact dynamics. In their study superhydrophobic, aluminum, and glass surfaces with three different surface temperatures (i.e., 20, 2, and $-2{ }^{\circ} \mathrm{C}$ ) were used. Furthermore, three different relative humidities (i.e., $10 \%, 20 \%$, and 30\%) were applied while the droplet Weber and Reynolds numbers, and the air temperature were fixed. It was revealed that the ratio of the surface temperature to the dew point temperature, which depends on relative humidity and air temperature, has a significant impact on droplet spreading, recoil, and contact angle. In general, when the mentioned ratio is less than one and decreases (it can be done by increasing the relative humidity or decreasing the surface temperature), condensation and frost formation become important, droplet spreading diameter increases significantly, and the equilibrium contact angle decreases.

\subsection{Effect of Dimensionless Numbers}

The effect of dimensionless numbers on the spreading ratio, $S$, during droplet deposition on a dry surface is shown in Figure 8 [60]. To obtain these results, one dimensionless number was individually changed while other dimensionless numbers as well as contact angles were kept constant. As shown in Figure 8a, the maximal spreading ratio increases with Reynolds number. On the other hand, the minimal spreading ratio at the end of the receding phase slightly decreases as the Reynolds number increases. Furthermore, the Reynolds number does not significantly affect the duration of spreading and receding phases in terms of dimensionless time. In contrast, as can be seen in Figure $8 b$, the Weber number does not affect the spreading phase. However, by increasing the Weber number, receding is slowed down. Increasing the Bond number, results in a slight increase of the spreading ratio in all impact stages (see Figure 8c). In short, the competition of inertial and viscous forces has significant influence on the spreading phase, while the surface tension force mainly affects the receding phase [60].

Herbert et al. [60] also showed that by increasing the Reynolds number, the total heat transfer from the substrate to the droplet significantly decreases. It was explained that although the heat transfer area is larger during the spreading and the beginning of the receding stages for large values of Reynolds, the heat flow is noticeably lower in these phases. In addition, it was shown that increasing the Weber number causes the dimensionless heat flow during the spreading and the receding phases to decrease and enhance, respectively. Moreover, increasing the Prandtl number results in significant reduction of heat transfer due to a suppressed convective heat transfer at the solid-liquid interface. It was also revealed that a higher value of Bond number causes the heat transfer rate to increase throughout the entire process since the wetted area is enlarged, as shown in Figure 8c. 

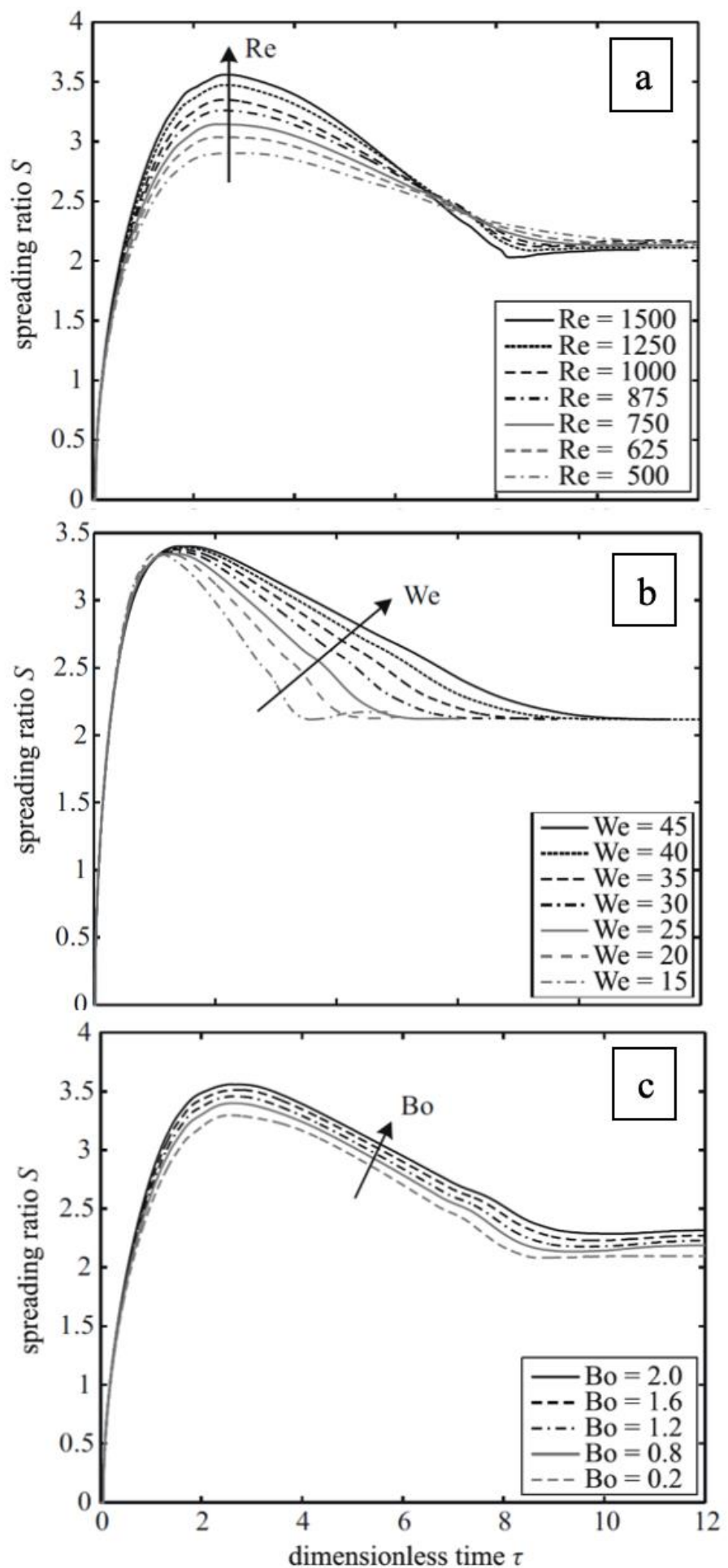

Figure 8. Effect of dimensionless numbers on the droplet spreading ratio; (a) effect of the Reynolds number $(W e=15, B o=0.5, P r=9.54)$, (b) effect of the Weber number $(R e=1000, B o=0.5, P r=9.54)$, and (c) effect of the Bond number $(W e=15, R e=1000, \operatorname{Pr}=9.54$; reproduced with permission from [60]).

\section{Droplet Impact on Moving Surfaces}

Droplet impact onto moving surfaces shows vast differentiations in their dynamics. The degree of droplet deformation and induction of splashing are heavily dependent on droplet impact velocity and surface tangential velocity. Povarov et al. [112] observed the presence of the air layer causing the droplet to lift off at high tangential velocities. At low surface velocity, the droplet is deposited 
onto the surface with no lift off. The bottom layer of the droplet adheres to the surface and spreads in a tear-like shape. At higher velocities, there is partial lift off of the droplet. The bottom layer of the droplet adheres to the surface and moves with it while the remainder of the droplet stays above the impact point. As the bottom layer is dragged away, sufficiently high tangential velocities cause the formation of an air layer. This triggers the rear edge of the droplet to splash and partially rebound off the surface. Total rebounding occurs at even higher tangential velocities as the droplet becomes significantly deformed [112]. Figure 9 illustrates droplet deformation on a moving surface. Mundo et al. [113] studied the splashing threshold of a droplet during impact on a moving substrate. Based on their observations, for high impact velocities, as the droplet impacts on the surface, a liquid film forms and spreads. The liquid film then deforms with the moving surface forming corona around the droplet. As the droplet continues to impact the surface, the fluid is fed into the corona film allowing it to grow. Whereas when less fluid is fed into the corona film, it becomes thinner and eventually disintegrates into secondary droplets. At lower impact velocities, the droplet impacts and spreads on the surface since there is not enough normal momentum to allow the corona formation and the kinetic energy is lost during the deformation process $[86,113]$. Mundo et al. also investigated the effects of surface roughness on droplet impacts on moving surfaces. They figured out that at increased surface roughness the droplet shows irregular deformation. Here the formation of the corona film and sequential instabilities were not observed due to vigorous splashing. Increased surface roughness also showed an increase in the formation of secondary droplets. On the other hand, decreased surface roughness promotes deposition of the droplet and splashing can be suppressed [113].
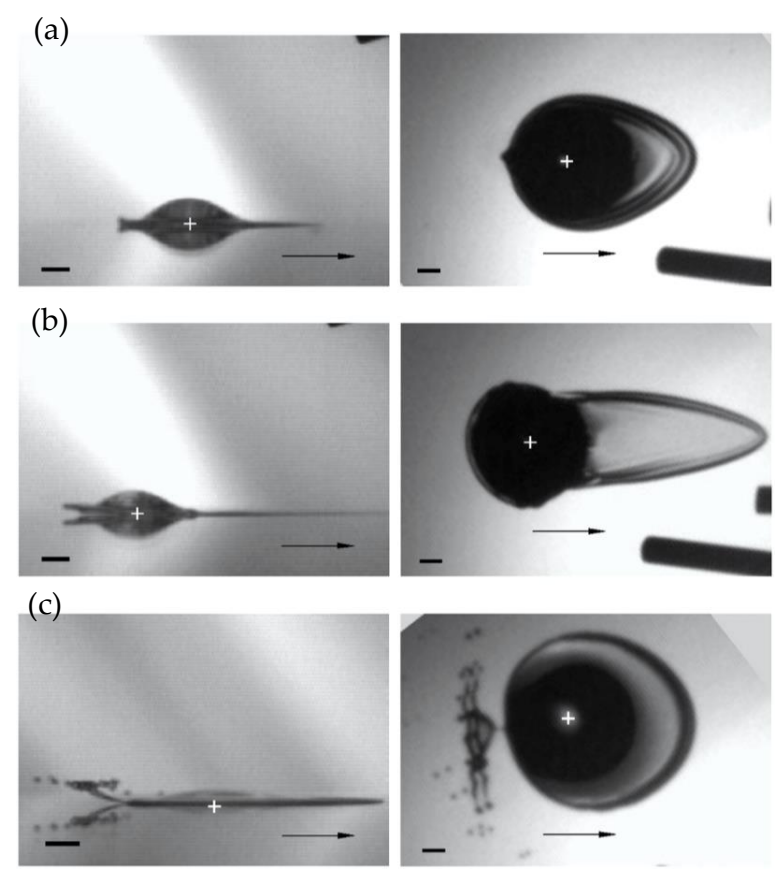

Figure 9. Side (Left) and top (Right) view of droplet deformation on a moving surface showing (a) deposition, (b) partial lift off, and (c) partial lift off with side-splash; scale bar is 1mm (reproduced with permission from [86]).

Zen et al. [86] studied how impacting velocity affected the splashing on moving surfaces. They described two splash phenomena, splash-around and side-splash in the rear edge. The threshold between splash-around and side-splash is dependent on the impact and surface velocities. In general, increasing the impact velocity induces side-splash and further increases in velocity lead to splash-around. It was also observed that increase of the impact velocity promotes the formation of smaller secondary droplets. Increasing the tangential velocity lead to promotion of side-splashing in the rear edge and lower tangential velocities promotes splash-around in all edges. Yao and Cai [114] demonstrated the 
predominance of tangential velocity on splashing threshold. They observed that as the surface velocity increased, the critical impact velocity to induce splashing significantly decreased.

\section{Conclusions}

The importance of droplet impact dynamics in a vast number of industrial applications such as spray coating and painting, spray cooling, ink-jet printing, combustion engines, etc., drives numerous studies into this area. This paper summarized the intensive training course aimed at discussing some of the main governing factors on droplet impact dynamics and heat transfer on both static and moving solid surfaces. In details on solid static surfaces, the effects of surface temperature, wettability, impact velocity, dimensionless numbers, and droplet shape and volume were discussed. Surface temperature played a major role on droplet dynamics, particularly at super-heated or super-cooled temperatures. At ample temperatures, the Leidenfrost effect or the freezing process can be induced, wildly changing the droplet dynamics. Surface wettability also greatly affected the droplet dynamics as spreading, retraction, and rebounding can be promoted or suppressed depending on impact conditions. Impact velocity of the droplet heavily affects spreading and splashing regimes owing to transfer of kinetic energy after impact.

The effects of tangential and impact velocity on the impact dynamics on moving surfaces were also discussed in this article. Droplet impact dynamics are heavily dependent on the impact and surface velocity. Splashing is easily promoted on moving surfaces due to deformations in droplet caused by the moving surface. In general, having training on droplet impact subject for engineering students is essential due to the real-world applications of this topic.

Author Contributions: Conceptualization, supervision, writing-review and editing, S.M.; writing-original draft preparation, C.L. and M.J. All authors have read and agreed to the published version of the manuscript.

Funding: This research received no external funding.

Acknowledgments: The authors gratefully acknowledge the support of the "Honors Program" at California State University Long Beach.

Conflicts of Interest: The authors declare no conflict of interest.

\section{References}

1. Worthington, A.M. On the forms assumed by rops of liquids falling vertically on a horizontal plate. Proc. R. Soc. Lond. 1876, 25, 261-272.

2. Worthington, A.M. A Study of Splashes; Longmans, Green, and Company: London, UK, 1908. Available online: https://archive.org/details/studyofsplashes00wortrich/mode/2up (accessed on 1 July 2020).

3. Yarin, A.L. Drop Impact Dynamics: Splashing, Spreading, Receding, Bouncing ... . Annu. Rev. Fluid Mech. 2006, 38, 159-192. [CrossRef]

4. Khojasteh, D.; Kazerooni, M.; Salarian, S.; Kamali, R. Droplet impact on superhydrophobic surfaces: A review of recent developments. J. Ind. Eng. Chem. 2016, 42, 1-14. [CrossRef]

5. Bolleddula, D.A.; Berchielli, A.; Aliseda, A. Impact of a heterogeneous liquid droplet on a dry surface: Application to the pharmaceutical industry. Adv. Colloid Interface Sci. 2010, 159, 144-159. [CrossRef]

6. Moghtadernejad, S.; Jadidi, M.; Esmail, N.; Dolatabadi, A. Shear-driven droplet coalescence and rivulet formation. Proc. Inst. Mech. Eng. Part. C J. Mech. Eng. Sci. 2016. [CrossRef]

7. Moghtadernejad, S. Dynamics of Droplet Shedding and Coalescence under the Effect of Shear Flow; Concordia University: Montréal, QC, Canada, 2014.

8. Bragg, M.B. Aicraft aerodynamic effects due to large droplet ice accretions. In Proceedings of the 34th Aerospace Sciences Meeting and Exhibit, Reno, NV, USA, 15-18 January 1996. [CrossRef]

9. Bragg, M.; Basar, T.; Perkins, W.; Selig, M.; Voulgaris, P.; Melody, J.; Sarter, N. Smart icing systems for aircraft icing safety. In Proceedings of the 40th AIAA Aerospace Sciences Meeting and Exhibit, Reno, NV, USA, 14-17 January 2002. [CrossRef]

10. Cao, Y.; Tan, W.; Wu, Z. Aircraft icing: An ongoing threat to aviation safety. Aerosp. Sci. Technol. 2018. [CrossRef] 
11. Moghtadernejad, S.; Jadidi, M.; Tembely, M.; Esmail, N.; Dolatabadi, A. Concurrent droplet coalescence and solidification on surfaces with various wettabilities. J. Fluids Eng. Trans. ASME 2015. [CrossRef]

12. Myong, R.S. Droplet impingement in aircraft icing. In Progress in Aircraft Icing and Aircraft Erosion Research; Springs of Dreams Corporation: Orange County, CA, USA, 2017.

13. Potapczuk, M.G. Aircraft icing research at NASA Glenn research center. J. Aerosp. Eng. 2013. [CrossRef]

14. Liu, Y.C.; Farouk, T.; Savas, A.J.; Dryer, F.L.; Avedisian, C.T. On the spherically symmetrical combustion of methyl decanoate droplets and comparisons with detailed numerical modeling. Combust. Flame 2013, 160, 641-655. [CrossRef]

15. Cen, C.; Wu, H.; Lee, C.f.; Liu, F.; Li, Y. Experimental investigation on the characteristic of jet break-up for butanol droplet impacting onto a heated surface in the film boiling regime. Int. J. Heat Mass Transf. 2018, 123, 129-136. [CrossRef]

16. Zama, Y.; Odawara, Y.; Furuhata, T. Experimental investigation on velocity inside a diesel spray after impingement on a wall. Fuel 2017, 203, 757-763. [CrossRef]

17. Pei, Y.; Qin, J.; Li, X.; Zhang, D.; Wang, K.; Liu, Y. Experimental investigation on free and impingement spray fueled with methanol, ethanol, isooctane, TRF and gasoline. Fuel 2017, 208, 174-183. [CrossRef]

18. Labergue, A.; Gradeck, M.; Lemoine, F. Experimental investigation of spray impingement hydrodynamic on a hot surface at high flow rates using phase Doppler analysis and infrared thermography. Int. J. Heat Mass Transf. 2016, 100, 65-78. [CrossRef]

19. Moghtadernejad, S.; Tembely, M.; Jadidi, M.; Esmail, N.; Dolatabadi, A. Shear driven droplet shedding and coalescence on a superhydrophobic surface. Phys. Fluids 2015. [CrossRef]

20. Moghtadernejad, S.; Mohammadi, M.; Jadidi, M.; Tembely, M.; Dolatabadi, A. Shear Driven Droplet Shedding on Surfaces with Various Wettabilities. SAE Int. J. Aerosp. 2013. [CrossRef]

21. Moghtadernejad, S.; Jadidi, M.; Ahmmed, K.M.T.; Lee, C.; Dolatabadi, A.; Kietzig, A.M. Experimental study of droplet shedding on laser-patterned substrates. Phys. Fluids 2019. [CrossRef]

22. Knausgård, K. Superhydrophobic Anti-Ice Nanocoatings. Master's Thesis, Norwegian University of Science and Technology, Trondheim, Norway, 2012.

23. Antonini, C.; Innocenti, M.; Horn, T.; Marengo, M.; Amirfazli, A. Understanding the effect of superhydrophobic coatings on energy reduction in anti-icing systems. Cold Reg. Sci. Technol. 2011. [CrossRef]

24. Sarkar, D.K.; Farzaneh, M. Superhydrophobic coatings with reduced ice adhesion. J. Adhes. Sci. Technol. 2009. [CrossRef]

25. Cao, L.; Jones, A.K.; Sikka, V.K.; Wu, J.; Gao, D. Anti-Icing superhydrophobic coatings. Langmuir 2009, 25, 12444-12448. [CrossRef]

26. Moghtadernejad, S.; Jadidi, M.; Dolatabadi, A.; Esmail, N. SPH Simulation of Rivulet Dynamics on Surfaces with Various Wettabilities. SAE Int. J. Aerosp. 2015. [CrossRef]

27. Chandra, S.; Fauchais, P. Formation of solid splats during thermal spray deposition. J. Therm. Spray Technol. 2009. [CrossRef]

28. Pasandideh-Fard, M.; Pershin, V.; Chandra, S.; Mostaghimi, J. Splat shapes in a thermal spray coating process: Simulations and experiments. J. Therm. Spray Technol. 2002. [CrossRef]

29. Jadidi, M.; Moghtadernejad, S.; Dolatabadi, A. A comprehensive review on fluid dynamics and transport of suspension/liquid droplets and particles in High-Velocity Oxygen-Fuel (HVOF) thermal spray. Coatings 2015, 5, 576-645. [CrossRef]

30. Jadidi, M.; Vardelle, A.; Dolatabadi, A.; Moreau, C. Heat transfer in suspension plasma spraying. In Handbook of Thermal Science and Engineering; Springer International Publishing: Cham, Switzerland, 2018.

31. Fauchais, P.L.; Heberlein, J.V.R.; Boulos, M.I. Thermal Spray Fundamentals: From Powder to Part; Springer: Berlin/Heidelberg, Germany, 2014.

32. Jadidi, M.; Moghtadernejad, S.; Dolatabadi, A. Penetration and breakup of liquid jet in transverse free air jet with application in suspension-solution thermal sprays. Mater. Des. 2016. [CrossRef]

33. Jabbari, F.; Jadidi, M.; Wuthrich, R.; Dolatabadi, A. A numerical study of suspension injection in plasma-spraying process. J. Therm. Spray Technol. 2014. [CrossRef]

34. Jadidi, M.; Yeganeh, A.Z.; Dolatabadi, A. Numerical Study of Suspension HVOF Spray and Particle Behavior Near Flat and Cylindrical Substrates. J. Therm. Spray Technol. 2018. [CrossRef] 
35. Parizi, H.B.; Rosenzweig, L.; Mostaghimi, J.; Chandra, S.; Coyle, T.; Salimi, H.; Pershin, L.; McDonald, A.; Moreau, C. Numerical simulation of droplet impact on patterned surfaces. J. Therm. Spray Technol. 2007. [CrossRef]

36. Jadidi, M.; Moghtadernejad, S.; Dolatabadi, A. Numerical Modeling of Suspension HVOF Spray. J. Therm. Spray Technol. 2016. [CrossRef]

37. Pasandideh-Fard, M.; Chandra, S.; Mostaghimi, J. A three-dimensional model of droplet impact and solidification. Int. J. Heat Mass Transf. 2002. [CrossRef]

38. Jadidi, M.; Mousavi, M.; Moghtadernejad, S.; Dolatabadi, A. A Three-Dimensional Analysis of the Suspension Plasma Spray Impinging on a Flat Substrate. J. Therm. Spray Technol. 2014. [CrossRef]

39. Yan, Z.; Zhao, R.; Duan, F.; Wong, T.N.; Toh, K.C.; Choo, K.F.; Chan, P.K.; Chua, Y.S. Spray Cooling. In Two Phase Flow, Phase Change and Numerical Modeling; Ahsan, A., Ed.; IntechOpen: London, UK, 2011. Available online: https://www.intechopen.com/books/two-phase-flow-phase-change-and-numerical-modeling/spraycooling (accessed on 1 July 2020). [CrossRef]

40. Horacek, B.; Kiger, K.T.; Kim, J. Single nozzle spray cooling heat transfer mechanisms. Int. J. Heat Mass Transf. 2005. [CrossRef]

41. Jia, W.; Qiu, H.H. Experimental investigation of droplet dynamics and heat transfer in spray cooling. Exp. Therm. Fluid Sci. 2003. [CrossRef]

42. Kim, J. Spray cooling heat transfer: The state of the art. Int. J. Heat Fluid Flow 2007. [CrossRef]

43. Sodtke, C.; Stephan, P. Spray cooling on micro structured surfaces. Int. J. Heat Mass Transf. 2007. [CrossRef]

44. Breitenbach, J.; Roisman, I.V.; Tropea, C. From drop impact physics to spray cooling models: A critical review. Exp. Fluids 2018. [CrossRef]

45. Incropera, F.P.; DeWitt, D.P.; Bergman, T.L.; Lavine, A.S. Fundamentals of Heat and Mass Transfer, 6th ed.; Wiley: Hoboken, NJ, USA, 2007.

46. Wijshoff, H. Drop dynamics in the inkjet printing process. Curr. Opin. Colloid Interface Sci. 2018. [CrossRef]

47. Gan, H.Y.; Shan, X.; Eriksson, T.; Lok, B.K.; Lam, Y.C. Reduction of droplet volume by controlling actuating waveforms in inkjet printing for micro-pattern formation. J. Micromech. Microeng. 2009. [CrossRef]

48. Castrejón-Pita, J.R.; Martin, G.D.; Hoath, S.D.; Hutchings, I.M. A simple large-scale droplet generator for studies of inkjet printing. Rev. Sci. Instrum. 2008. [CrossRef]

49. Daly, R.; Harrington, T.S.; Martin, G.D.; Hutchings, I.M. Inkjet printing for pharmaceutics-A review of research and manufacturing. Int. J. Pharm. 2015. [CrossRef]

50. Yusof, A.; Keegan, H.; Spillane, C.D.; Sheils, O.M.; Martin, C.M.; O'Leary, J.J.; Zengerle, R.; Koltay, P. Inkjet-like printing of single-cells. Lab. Chip 2011. [CrossRef]

51. Williams, C. Ink-jet printers go beyond paper. Phys. World 2006. [CrossRef]

52. Fan, Y.Q.; Wang, H.L.; Gao, K.X.; Liu, J.J.; Chai, D.P.; Zhang, Y.J. Applications of Modular Microfluidics Technology. Chin. J. Anal. Chem. 2018, 46, 1863-1871. [CrossRef]

53. Teh, S.Y.; Lin, R.; Hung, L.H.; Lee, A.P. Droplet microfluidics. Lab. Chip. 2008. [CrossRef]

54. Lee, C.Y.; Chang, C.L.; Wang, Y.N.; Fu, L.M. Microfluidic mixing: A review. Int. J. Mol. Sci. 2011, 12, 3263-3287. [CrossRef] [PubMed]

55. Grant, G.; Brenton, J.; Drysdale, D. Fire suppression by water sprays. Prog. Energy Combust. Sci. 2000. [CrossRef]

56. Moon, J.H.; Kim, D.Y.; Lee, S.H. Spreading and receding characteristics of a non-Newtonian droplet impinging on a heated surface. Exp. Therm. Fluid Sci. 2014. [CrossRef]

57. Rein, M. Phenomena of liquid drop impact on solid and liquid surfaces. Fluid Dyn. Res. 1993. [CrossRef]

58. Moon, J.H.; Lee, J.B.; Lee, S.H. Dynamic Behavior of Non-Newtonian Droplets Impinging on Solid Surfaces. Mater. Trans. 2013. [CrossRef]

59. Josserand, C.; Thoroddsen, S.T. Drop Impact on a Solid Surface. Annu. Rev. Fluid Mech. 2016. [CrossRef]

60. Herbert, S.; Gambaryan-Roisman, T.; Stephan, P. Influence of the governing dimensionless parameters on heat transfer during single drop impingement onto a hot wall. Colloids Surf. A Physicochem. Eng. Asp. 2013. [CrossRef]

61. Marengo, M.; Antonini, C.; Roisman, I.V.; Tropea, C. Drop collisions with simple and complex surfaces. Curr. Opin. Colloid Interface Sci. 2011. [CrossRef]

62. Wang, H.; Zhu, X.; Chen, R.; Liao, Q.; Ding, B. How supercooled superhydrophobic surfaces affect dynamic behaviors of impacting water droplets? Int. J. Heat Mass Transf. 2018, 124, 1025-1032. 
63. Bange, P.G.; Patil, N.D.; Bhardwaj, R. Impact Dynamics of a Droplet on a Heated Surface. In Proceedings of the 5th International Conference of Fluid Flow, Heat and Mass Transfer (FFHMT'18), Niagara Falls, ON, Canada, 7-9 June 2018; Volume 190, pp. 232-247. [CrossRef]

64. Guo, Y.; Shen, S.; Yang, Y.; Liang, G.; Zhen, N. Rebound and spreading during a drop impact on wetted cylinders. Exp. Therm. Fluid Sci. 2013, 52, 97-103. [CrossRef]

65. Rioboo, R.; Tropea, C.; Marengo, M. Outcomes from a drop impact on solid surfaces. At. Sprays 2001. [CrossRef]

66. Zhao, P.; Hargrave, G.K.; Versteeg, H.K.; Garner, C.P.; Reid, B.A.; Long, E.J.; Zhao, H. The dynamics of droplet impact on a heated porous surfac. Chem. Eng. Sci. 2018. [CrossRef]

67. Rajesh, R.S.; Naveen, P.T.; Krishnakumar, K.; Ranjith, S.K. Dynamics of single droplet impact on cylindrically-curved superheated surfaces. Exp. Therm. Fluid Sci. 2019, 101, 251-262. [CrossRef]

68. Pan, Y.; Shi, K.; Duan, X.; Naterer, G.F. Experimental investigation of water droplet impact and freezing on micropatterned stainless steel surfaces with varying wettabilities. Int. J. Heat Mass Transf. 2019, 129, 953-964. [CrossRef]

69. Laan, N.; de Bruin, K.G.; Bartolo, D.; Josserand, C.; Bonn, D. Maximum diameter of impacting liquid droplets. Phys. Rev. Appl. 2014, 2, 044018. [CrossRef]

70. Lee, J.B.; Laan, N.; de Bruin, K.G.; Skantzaris, G. Universal rescaling of drop impact on smooth and rough surfaces. J. Fluid Mech. 2016, 786, R4. [CrossRef]

71. Jones, H. Cooling, freezing and substrate impact of droplets formed by rotary atomization. J. Phys. D Appl. Phys. 1971. [CrossRef]

72. Chandra, S.; Avedisian, C.T. On the collision of a droplet with a solid surface. Proc. R. Soc. A Math. Phys. Eng. Sci. 1991. [CrossRef]

73. Asai, A.; Shioya, M.; Hirasawa, S.; Okazaki, T. Impact of an ink drop on paper. J. Imaging Sci. Technol. 1993, 37, 205-207.

74. Pasandideh-Fard, M.; Qiao, Y.M.; Chandra, S.; Mostaghimi, J. Capillary effects during droplet impact on a solid surface. Phys. Fluids 1996. [CrossRef]

75. Mao, T.; Kuhn, D.C.S.; Tran, H. Spread and Rebound of Liquid Droplets upon Impact on Flat Surfaces. AIChE J. 1997. [CrossRef]

76. Ukiwe, C.; Kwok, D.Y. On the maximum spreading diameter of impacting droplets on well-prepared solid surfaces. Langmuir 2005. [CrossRef] [PubMed]

77. Tang, C.; Qin, M.; Weng, X.; Zhang, X.; Zhang, P.; Li, J.; Huang, Z.; Qin, M.; Weng, X.; Zhang, X.; et al. Dynamics of droplet impact on solid surface with different roughness. Int. J. Multiph. Flow 2017, 96, 56-69. [CrossRef]

78. Jin, Z.; Zhang, H.; Yang, Z. International Journal of Heat and Mass Transfer The impact and freezing processes of a water droplet on different cold cylindrical surfaces. Int. J. Heat Mass Transf. 2017, 113, 318-323. [CrossRef]

79. Jin, Z.; Wang, Z.; Sui, D.; Yang, Z. The impact and freezing processes of a water droplet on different inclined cold surfaces. Int. J. Heat Mass Transf. 2016, 97, 211-223.

80. Zhang, H.; Jin, Z.; Jiao, M.; Yang, Z. Experimental investigation of the impact and freezing processes of a water droplet on different cold concave surfaces. Int. J. Therm. Sci. 2018, 132, 498-508. [CrossRef]

81. Jin, Z.; Zhang, H.; Yang, Z. Experimental investigation of the impact and freezing processes of a water droplet on an ice surface. Int. J. Heat Mass Transf. 2017. [CrossRef]

82. Ju, J.; Jin, Z.; Zhang, H.; Yang, Z.; Zhang, J. The impact and freezing processes of a water droplet on different cold spherical surfaces. Exp. Therm. Fluid Sci. 2018. [CrossRef]

83. Zhang, R.; Hao, P.; Zhang, X.; He, F. Supercooled water droplet impact on superhydrophobic surfaces with various roughness and temperature. Int. J. Heat Mass Transf. 2018, 122, 395-402. [CrossRef]

84. Liang, G.; Guo, Y.; Mu, X.; Shen, S. Experimental investigation of a drop impacting on wetted spheres. Exp. Therm. Fluid Sci. 2014, 55, 150-157. [CrossRef]

85. Burzynski, D.A.; Bansmer, S.E. Droplet splashing on thin moving films at high Weber numbers. Int. J. Multiph. Flow 2018, 101, 202-211. [CrossRef]

86. Zen, T.S.; Chou, F.C.; Ma, J.L. Ethanol drop impact on an inclined moving surface. Int. Commun. Heat Mass Transf. 2010, 37, 1025-1030. [CrossRef]

87. Xu, L.; Zhang, W.W.; Nagel, S.R. Drop splashing on a dry smooth surface. Phys. Rev. Lett. 2005. [CrossRef]

88. Allen, R.F. The role of surface tension in splashing. J. Colloid Interface Sci. 1975. [CrossRef] 
89. Thoroddsen, S.T.; Sakakibara, J. Evolution of the fingering pattern of an impacting drop. Phys. Fluids 1998. [CrossRef]

90. Breitenbach, J.; Roisman, I.V.; Tropea, C. Drop collision with a hot, dry solid substrate: Heat transfer during nucleate boiling. Phys. Rev. Fluids 2017. [CrossRef]

91. Leidenfrost, J.G. On the fixation of water in diverse fire. Int. J. Heat Mass Transf. 1966. [CrossRef]

92. Kim, S.H.; Jiang, Y.; Kim, H. Droplet impact and LFP on wettability and nanostructured surface. Exp. Therm. Fluid Sci. 2018, 99, 85-93. [CrossRef]

93. Chen, H.; Cheng, W.l.; Peng, Y.h.; Jiang, L.j. Dynamic Leidenfrost temperature increase of impacting droplets containing high-alcohol surfactant. Int. J. Heat Mass Transf. 2018, 118, 1160-1168. [CrossRef]

94. Chaudhary, G.; Li, R. Freezing of water droplets on solid surfaces: An experimental and numerical study. Exp. Therm. Fluid Sci. 2014. [CrossRef]

95. Jung, S.; Tiwari, M.K.; Doan, N.V.; Poulikakos, D. Mechanism of supercooled droplet freezing on surfaces. Nat. Commun. 2012. [CrossRef] [PubMed]

96. Li, H.; Roisman, I.V.; Tropea, C. Influence of solidification on the impact of supercooled water drops onto cold surfaces. Exp. Fluids 2015. [CrossRef]

97. Mishchenko, L.; Hatton, B.; Bahadur, V.; Taylor, J.A.; Krupenkin, T.; Aizenberg, J. Design of ice-free nanostructured surfaces based on repulsion of impacting water droplets. ACS Nano 2010. [CrossRef] [PubMed]

98. Wenzel, R.N. Resistance of solid surfaces to wetting by water. Ind. Eng. Chem. 1936. [CrossRef]

99. Cassie, A.B.D.; Baxter, S. Wettability of porous surfaces. Trans. Faraday Soc. 1944. [CrossRef]

100. Gundersen, H.; Leinaas, H.P.; Thaulow, C. Surface structure and wetting characteristics of Collembola cuticles. PLoS ONE 2014, 9, e86783. [CrossRef]

101. Vakarelski, I.U.; Patankar, N.A.; Marston, J.O.; Chan, D.Y.C.; Thoroddsen, S.T. Stabilization of Leidenfrost vapour layer by textured superhydrophobic surfaces. Nature 2012. [CrossRef]

102. Phan, H.T.; Caney, N.; Marty, P.; Colasson, S.; Gavillet, J. Surface wettability control by nanocoating: The effects on pool boiling heat transfer and nucleation mechanism. Int. J. Heat Mass Transf. 2009. [CrossRef]

103. Kandlikar, S.G. A Theoretical Model to Predict Pool Boiling CHF Incorporating Effects of Contact Angle and Orientation. J. Heat Transf. 2001. [CrossRef]

104. Hamdan, K.S.; Kim, D.E.; Moon, S.K. Droplets behavior impacting on a hot surface above the Leidenfrost temperature. Ann. Nucl. Energy 2015, 80, 338-347. [CrossRef]

105. Yun, S.; Hong, J.; Kang, K.H. Suppressing drop rebound by electrically driven shape distortion. Phys. Rev. E Stat. Nonlinear Soft Matter Phys. 2013. [CrossRef]

106. Yun, S.; Lim, G. Ellipsoidal drop impact on a solid surface for rebound suppression. J. Fluid Mech. 2014. [CrossRef]

107. Yun, S.; Lim, G. Control of a bouncing magnitude on a heated substrate via ellipsoidal drop shape. Appl. Phys. Lett. 2014. [CrossRef]

108. Yun, S. Bouncing of an ellipsoidal drop on a superhydrophobic surface. Sci. Rep. 2017. [CrossRef]

109. Yun, S. Impact dynamics of egg-shaped drops on a solid surface for suppression of the bounce magnitude. Int. J. Heat Mass Transf. 2018, 127, 172-178. [CrossRef]

110. Bobinski, T.; Sobieraj, G.; Gumowski, K.; Rokicki, J.; Psarski, M.; Marczak, J.; Celichowski, G. Droplet impact in icing conditions-The influence of ambient air humidity. Arch. Mech. 2014. [CrossRef]

111. Jadidi, M.; Trepanier, J.Y.; Farzad, M.A.; Dolatabadi, A. Effects of ambient air relative humidity and surface temperature on water droplet spreading dynamics. FEDSM 2018. [CrossRef]

112. Povarov, O.A.; Nazarov, O.I.; Ignat'evskaya, L.A.; Nikol'skii, A.I. Interaction of drops with boundary layer on rotating surface. J. Eng. Phys. 1976. [CrossRef]

113. Mundo, C.; Sommerfeld, M.; Tropea, C. Droplet-wall collisions: Experimental studies of the deformation and breakup process. Int. J. Multiph. Flow 1995. [CrossRef]

114. Yao, S.C.; Cai, K.Y. The dynamics and leidenfrost temperature of drops impacting on a hot surface at small angles. Exp. Therm. Fluid Sci. 1988. [CrossRef]

(C) 2020 by the authors. Licensee MDPI, Basel, Switzerland. This article is an open access article distributed under the terms and conditions of the Creative Commons Attribution (CC BY) license (http://creativecommons.org/licenses/by/4.0/). 